\title{
The Place of Animal Being: Following Animal Embryogenesis and Navigation to the Hollow of Being in Merleau-Ponty ${ }^{1}$
}

David Morris, Department of Philosophy, Concordia University, davimorr@alcor.concordia.ca

Published in Research in Phenomenology 40 (2010): 188-218

The final publication is available at

brill.publisher.ingentaconnect.com/content/brill/rip, DOI 10.1163/156916410X509922

\begin{abstract}
This article pursues overlapping points about ontology, philosophical method, and our kinship with and difference from nonhuman animals. The ontological point is that being is determinately different in different places not because of differences, or even a space, already given in advance, but in virtue of a negative in being that is regional and rooted in place, which Merleau-Ponty calls the "hollow." The methodological point is that we tend to miss this ontological point because we are inclined to what I call transportable thinking, which conceives of things and spatial determinacy itself as being what they are independent of where they are. I argue that we are inclined this way because, in contrast to other animals, we have a weak sense of where we are. We are lost animals. To compensate for lostness, we abstract ourselves from place and conceptualize ourselves and things by way of a transportable, Cartesian "view from above."
\end{abstract}

\section{Keywords}

Merleau-Ponty, animals, phenomenology, place, differance, ontology

Being is determinately different in different places-it is diverse. This article develops a point about the ontology of diversity by studying phenomena of animal navigation and embryogenesis. The point is that the diversity of being is engendered by something regional, rooted in place, in virtue of what Merleau-Ponty calls a "hollow" in being, that is, a generative openness endogenous to the spread of being. Diversity is not generated by being as an already given plenum that is one and the same everywhere, such that being is everywhere informed by or contains non-regional, universal ideas or laws that can already actively specify or generate diversity. Rather, it is in virtue of not being all given and in virtue of this nongivenness being passive to being's inherent, regionalizing spread — to the "transspatial,"2 as Merleau-Ponty puts it—-that being engenders diversity. Diversity is thus reciprocal with place.

To say that being is hollow, non-given, is not to say that being is purely void or empty: the very hollow of being inherently opens sense. ${ }^{3}$ The hollow is a negativity that gives being direction. But the hollow is precisely what Merleau-Ponty conceives as a negativity in being, and it eludes reduction to anything positively given. So diversity involves a genesis of differences from differences that are yet to be determined. The 'not-yetness' of the hollow is philosophically important in that its operation is not merely temporal (as in Derridean différance), but also importantly transspatial (here there is a resonance with Heideggerian Abgrund). ${ }^{4}$ Yet, as I suggest below, the sort of animal that we are and the sort of experience of spatiality that we thence have inclines us to miss this transspatial hollowness of being and model the determinacy-engendering power of being on, for example, rational laws or on our internal experience of temporality. ${ }^{5}$

Here we arrive at a nexus in which ontology, method, and our relation to and difference from other animals mutually 
inform and illuminate one another. This nexus is central to the article's spiralling path, so I begin by introducing it in two steps. First, I trace a point about MerleauPonty's philosophical method as it intersects with and leads him to the study of animals. Second, I introduce an ontological and conceptual point central to all that follows, namely, that our language, tradition, and bodies gear us to asking questions about what things are, as if things are substances that are what they are, independent of where they are. This kind of question involves what I call transportable thinking (or, correlatively, substance thinking). In contrast, what I call placed thinking conceives things as regional functions of places. ${ }^{6}$ Grasping the fact that diversity has its genesis in a transspatial hollow of being entails and involves a shift from transportable to placed thinking.

Both this shift and the concept of a transspatial hollow in being are motivated by studying the development of hydra embryos, and then studying how sea turtles navigate across thousands of kilometers back to their home beaches. The strategy here is to have animal being-including our animal being — give 'insider testimony' to the way being goes. The conceptual point of the study of sea turtle navigation is drawn out by way of a contrast between Western and Micronesian experiences of navigation, and a contrast between the navigational ability of human animals and other animals. These contrasts loop back to the point that it is our way of being animal-our being a 'lost animal' weakly tuned to place- that inclines us to transportable thinking. I suggest that this also inclines us to Cartesian dualisms: to conduct ourselves in relative abstraction from specific places or points of view is to already displace ourselves from our worldly, bodily, animal being and to tend to what Merleau-Ponty calls "thinking from above." The concluding thought is that we human animals are different from other animals not by way of having a fundamentally different faculty or kind of being, but precisely by way of a "weakness" of our animal being. That is, we are different from other animals precisely by way of what Merleau-Ponty calls our "strange kinship" with animals. ${ }^{7}$ We are different from other animals in not quite being able to follow them. ${ }^{8}$

In developing this point about the hollow of being, I take myself to be pursuing something Merleau-Ponty had been working out across his career, in particular in his later lectures on nature $(L N)$, and institution and passivity (IP). ${ }^{9}$ And I am doing so through methodological strategies learned from Merleau-Ponty. But the path and steps I take are different from MerleauPonty's.

\section{Merleau-Ponty's Philosophy of Animality}

Merleau-Ponty often seeks clues to philosophical problems, for example, about perception, by studying animals. This strategy stems from his commitment to phenomenology as tuning concepts to the phenomena, rather than cutting the phenomena to fit already presumed and perhaps prejudiced theoretical frameworks. Undoing such presumptions or prejudices is difficult because some run so deep they are barely noticed. Studying animals helps temper this difficulty. Animals (including ourselves) inform us about being from within: an animal's way of being offers clues as to the way being operates, in advance of our concepts. This helps us undo conceptual prejudices and develop new concepts. ${ }^{10}$

But Merleau-Ponty's philosophy is not merely about animals. This is because his 'animal strategy' is driven by an increasing radicalization of the phenomenological method, which radicalization displaces the agency of the phenomenologist into nature 
and being. ${ }^{11}$ To the degree that the phenomenologist operates as if purely active from within, she or he is liable to misdescribe phenomena. ${ }^{12}$ The philosopher should then seek things that, as it were, insistently describe themselves. She or he should let descriptions passively well up in him or herself, through a passivityspecifically, here, an animality-endogenous to philosophical activity. Thus Merleau-Ponty claims that "the only means to think Nature is by means of perceived nature" (LN 278/214). Not only must we find our concepts in nature itself, not 'in our heads,' we must operate with nature, in nature, to find these concepts.

This point about thinking nature by means of perceived nature (which appears in reflections on the relation between philosophy and nature in the third nature course) echoes in some remarks about Schelling in the first nature course. There he writes that "we rediscover Nature in our perceptual experience prior to reflection" and that "perception teaches us an ontology that it alone can reveal to us" ( $L N$ 63-64/3940). These remarks startle because they are about Schelling but sound like remarks about Merleau-Ponty. Moreover, MerleauPonty's Schelling study appears in a section on the romantic conception of nature, which oddly includes Bergson and Husserl. But for Merleau-Ponty, Bergson, and Husserl (who are key inspirations) echo Schelling's romantic conception of nature insofar as they find the beginning point of philosophy not in an idea actively constituted within us, but in some moment of reality or intuition in nature itself that testifies to the way things go. Schelling, Bergson, Husserl—and Merleau-Ponty—all seek to begin philosophy from a point somewhat passive to and inside nature. ${ }^{13}$ Hence Merleau-Ponty's methodological effort, in The Visible and the Invisible,${ }^{14}$ to install philosophy back in being so as to interrogate being from within, and his effort in the institution lectures to conceptualize philosophy as an institution arising from prior institutions of history, culture, maturation, and animality. Just as the painter reveals something metaphysically significant by "taking his body with him," ${ }^{\text {"15 }}$ thereby letting him paint and interrogate being from within, we could say that for Merleau-Ponty the philosopher must take along her or his animality if she or he is to properly interrogate being from within. Here again, we reach a nexus of ontology, method, and our relation to other animals: to get being right, we have to get our animal being right.

This nexus reflects a substantive point in Merleau-Ponty, namely, that across his philosophical development he seeks sense not in constituting consciousness but in structure, perception, and ultimately, being. In the beginning of the first nature course, this point is captured in his definition of nature as "what has a sense, without this sense being posited by thought. It [nature] is the autoproduction of a sense" ( $L N 19 / 3)$.

Animals are nodes in nature as the autoproduction of sense: their very being is to mobilize and make themselves visible as nodes of sense production. In their coloration, embryogenesis, and so on (which Merleau-Ponty studies in $L N$ ), animals show us how they make sense and make sense of nature. Animals thus manifest the sensemaking of nature-and being. ${ }^{16}$

To give an example, a key ontological claim in the nature lectures and The Visible and the Invisible is that being is not governed by purely invisible essences ontologically divided from being. Rather this 'essence' is an invisible endogenous to, of, the visible. In contrast to purely invisible essences, this invisible cannot be purified of its visibility. In this sense, being is internally hollow, negative, there is a sort of invisible surplus endogenous to it. The invisible appears in/as the non-appearing of this 
surplus in appearance-but, crucially, the invisible does appear in and of the visible (rather than being a transcendent or entirely inapparent essence). The invisible appears in/as the sense, manifest in the visible, that there is more to the visible than now appears visible. Merleau-Ponty finds that this complex onto-logic resonates in the embryogenesis of animals: the visible organization of the animal body inseparably implicates invisible morphogenetic processes that are not reducible to the embryo's visible fabric here and now, yet are not realizable as anything other than an invisible of the visible, since these processes are not independent of visible material. Animals thus manifest an onto-logic of being: they manifest the way that an invisible of the visible operates in being.

What we are going to see below is how animals manifest a related onto-logic that shows us that space itself is not a pure invisible over and above things. That is, space does not have the sort of determinacy of an abstract container or dimension: its determinacy is engendered from within a sweep of being that is opened by a transspatial hollow endogenous to being. The engendering of determinacy from within this transspatial hollow is key to the invisible of the visible as generating sense. To prepare to grasp this point we need to briefly reflect on how we typically think about things and space.

\section{From What to When to Where: Transportable Thinking vs. Placed Thinking}

Western philosophy and science have long investigated humans, other animals, even being itself, by asking questions of the form: what is $\mathrm{X}$ ? As Bergson and Heidegger ${ }^{17}$ would variously suggest, such questions are molded to the kind of 'what' we are so geared to handle in everyday life: we suppose our question is answered by some already given thing or being, modeled on a given solid or tool that would already solve a problem. Unsurprisingly, this approach leads to an ontology of presence that ultimately answers "what is X?" type of questions by appeal to already given essences or substances.

Problems in this approach have gradually led philosophy and science to attend to the 'when' of things. Heidegger's Being and Time gives a famous example: the being of Dasein is not a given 'what,' but an inherently temporal phenomenon. Dasein is when there is being-towards-death: Dasein's being is the being of a kind of temporalitya clue that the being of being is temporality, not an already present and determined substance. And as R. G. Collingwood insightfully remarks, nineteenth- and twentieth-century philosophy and science are in general characterized by a "principle of minimum time": natural things are not 'whats,' but realizations of functions, and there is a minimum time it takes for such realizations to appear. ${ }^{18}$ Biology and evolution provide classic examples: if species and individual organisms are not eternal essences or their instantiations, but ongoing results of evolution and development, then observing them on a time-scale shorter than that of speciation or life-cycles misses the phenomenon. But other examples proliferate in current science. Scientists argue, for example, that the growth and strength of tendon is a function of stressing it ${ }^{19}$ or that cognition is not a function of fixed neural structures but of the brain as a plastic system that is a function of our dynamic interaction with the world. ${ }^{20}$ What appear to be things are in fact functions of time or, rather, of the temporality of things. For what determines appearances are certain rhythms and dynamics that ought be measured in terms of rates and dynamics characteristic of systems in which we find these things, not in terms 
of a clock-time specified in abstraction from things - much like music is best counted by its own beat. If you do not observe things in their own temporality, you will miss what is important to them.

Attention to temporal dynamics, in turn, leads philosophy and science to the 'where' of things. Collingwood, for example, links the principle of minimum time to a "principle of minimum space." The idea behind this principle is subtle yet deep. If water is a homogenous instantiation of an abstract essence, then it can appear as such in any arbitrarily small amount of water, since what ontologically determines water as water is an abstract essence that is determinate independent of spacesomething metaspatial (beyond space), as Merleau-Ponty would put it. ${ }^{21}$ But if water is the realization of a function, then water only happens when certain differentiated fluxes are coordinated over time. As a function of coordination, water is a structure, a relation spread across some minimum number of atoms ( $\mathrm{H}$ and $\mathrm{O}$ atoms that are themselves structures). If you observe nature on too small a scale, you will not find water taking place.

But Collingwood's line of thinking (through Whitehead, who also inspires Merleau-Ponty) also leads to the point that if you could observe nature on too small a scale you will not find space taking place either: space is a function of structure too; it is not a substance, not even a peculiarly empty one; it does not stand on its own as container. This broaches a deep and difficult point that will not be fully resolved here, but needs to be sketched to contextualize the discussions of animal development and navigation that follow-which in turn will shed light on this initial sketch.

The point is that Collingwood's line of thinking leads to a concept of space not as a container independent of and given in advance of what it contains, but as a function or expression of a more elemental 'whereness' manifest in the spread of being, via the spreads of the various things there are. Space is a function of how things spread. Space is, as it were, formed as to its determinacy $^{22}$ (as to the way it positions things) by what there is. So, instead of conceptualizing space as a system with an already determinate power of positioning things in locations, we find that the determinate positions afforded by space are a regional function of what there is. The contrast here echoes one between Newtonian absolute space, and Leibnizian or Einsteinian space as an inherently relational system. But I will couch it in terms of a distinction between place and space developed by Edward S. Casey, ${ }^{23}$ and by Jeff Malpas ${ }^{24}$ in his studies of Heidegger's place-based thinking.

In this distinction, space is a system for determining locations that can be set up in advance of things, which thereby already locates movable things therein. In contrast, place is manifest in a concrete dynamic of movements and linkages that spread across things. What determines a place as the place that it is, and how a place reciprocally places things therein, involves an irreducible reciprocity between place and the primitive spread of things. This is cognate to the irreducible reciprocity between temporality and the primitive rates and rhythms of things. Temporality finds its measure in the change-dynamic of things; it is engendered in this change-dynamic, as an intensive flow proper to measuring such flow. Place finds its measure in the 'spread-dynamic'25 of things and is engendered in this spreaddynamic as proper to measuring such spread. In both cases we find a regionally engendered temporality and place that is dependent on a prior, more expansive temporality and place. We find that this place, this temporality devolves from a more capacious and already ongoing place and 
temporality. But here a key point comes into play: this already ongoing place and temporality is not an abstract absolute or universal, flowing from itself. Place and temporality are not yet or fully determinate. Place and temporality are in the mode of being: already-ongoing, not-yet determined; this is in contrast to being: already-given, already determinate. Temporality and place are in this sense hollow.

A case for the hollowness of place is developed below by study of animal phenomena. But that study requires reorienting our thinking. For the point I have been developing is not only meant to challenge our usual tendency to pursue things - and space itself-by asking what things and space are, and answering in terms of substances or essences. It is meant to challenge a deeper prejudice of thinking that, on my view, underlies such essence- or substance-thinking, namely, what I call ontological localism. Ontological localism presumes that the determinacy and ontological substrate of a thing can be localized in the space the thing occupies, in a recursively nested way that ultimately positions determinacy in arbitrarily small points, such that things, space, and being itself can appear as determinate in any arbitrarily small point.

Here I introduce a contrast between location and region to complement the above contrast between space and place. To explain this, I deploy position as a genus, to designate the determinacy of something with respect to either space or place. A location is the species of position proper to space. In virtue of a space already given in advance, a location can be positioned as, or in, an arbitrarily small point (in the way that water, in virtue of an essence, can be instantiated in an arbitrarily small amount). A region is the species of position proper to place; it lacks the discreteness or already given unity definitive of a location, it always reaches out beyond any localizable point. In contrast to localizable determinacy, the determinacy of a region-what positions a region as the region that it is - is a function of a broader region: the determinacy of a region is regional. A region, we could say, is not well bounded but rather has a horizonal character of bordering and thence opening up into broader and broader regions. ${ }^{26}$

Ontological localism is minimalist: it seeks to reduce spatial determinacy to atomic points, and thus operates with or is driven by a concept of space as already affording such atomic locatedness; space is the reticule of such locations, and enables what I call locative positioning of things. Conversely, ontological regionalism is maximally expansive, since regions are functions of the maximal region in which they operate. Whereas locations are locatively in the space that contains them, regions are of places: regions spring from, are engendered by, as well as express, place. Regional positioning is thus always approximate, partial, relative to various horizonal scales and involves movement or rest in a region. In contrast, locative positioning is definitive, discrete, and independent of scale. For example, I report my position differently when telling a friend where to meet me in a region of our neighborhood versus telling a Torontonian how to drive to my neighborhood region in Montréal. Places themselves articulate the different regions (e.g., café zones, city areas with distinct styles), scales, kinds of movement, and horizons that enable such regional positioning. In contrast, my GPS coordinates are the same at any scale.

Ontological localism is correlative to a style of thinking that I call transportable thinking, which has a twofold aspect. First, it is a style of thinking that, ontologically, conceptualizes things as transportable 'whats,' things that remain what they are when moved from location to location in 
space. It also conceptualizes space itself as peculiarly transportable: space is at once an absolute container over and above the transportable contents it locates, yet it is a frame of reference whose origin may be freely moved about (since space is isotropic, the same everywhere). ${ }^{27}$ Second, transportable thinking conceptualizes thinking as itself transportable, remaining the same wherever thinking might happen or whatever thinking might think about. Transportable thinking, in other words, entails the pensée de survole (thinking from above) that Merleau-Ponty constantly criticizes. What is being noted here is that it is characteristic of pensée de survole that it conceives both itself and its objects as only accidently modified or determined by position - and that it does so by identifying itself as thinking that is not positioned anywhere in particular but ranges over all of abstract space.

Placed thinking is quite different from transportable thinking. Again, this has a twofold aspect. First, placed thinking conceptualizes what things are, the determinacy of things, as a function of the region in which they are placed. Second, placed thinking conceptualizes thinking itself as a function of the region in which it is placed. We might think of Darwin as an exemplar of placed thinking. It is often noted that his insights depend on conceiving life as evolving over an extraordinarily long minimum of time, that is, conceptualizing history as integral with the determinacy of organisms. But, it is hard to read Darwin's Origin of Species, The Voyage of the Beagle, his other writings, and the copious literature on Darwin, without realizing that place is perhaps even more deeply ingredient in his thinking than time. Darwin could not possibly have posed his question about the diversity of species in the way that he didand his posing of the question is key to his remarkable answer- without first of all peregrinating from place to place (in person or through proxies) and grasping, on a perceptual and empirical level, that plants and animals are functions of the regions they inhabit. $^{28}$

\section{Placing Parts in Hydra Bodies}

So far I have sketched a divergence between two different ways of thinking, and their underlying ontologies: between transportable thinking that focuses on the 'what' of things and placed thinking that focuses on the 'where' of things, where this 'where' is understood in terms of regions of place, not locations in abstract space. But instead of making this point as abovewhich does not escape a pensée de survole insofar as it works within the history of ideas-I now pursue this shift from transportable to placed thinking by way of a radical reflection on - and from withinanimal being.

In this pursuit I am both following and extending a thought in MerleauPonty's nature lectures. As Merleau-Ponty puts it in a discussion of recent advances in physics (which echoes points from Collingwood, although as far as I know Merleau-Ponty did not know Collingwood), "Space is not something"; it is not a thing or 'what' independent of spatial things. We have to put in question "the idea of a nature in itself of space," independent of relations between things, and resist our "tendency to convert relations into things," to convert space into a substantive and purely invisible thing that would already support spatial relations in advance (LN 141-42/103-4). This reflects an ontological point central to the third lecture, namely, that we must go beyond "corpuscular being as an absolutely hard nucleus, in favor of statistical and collective being" without, however, reducing that collective to a sum of corpuscular parts ( $L N$ 275/213). 
In my terms, Merleau-Ponty is saying that we must move beyond ontological localism to regionalism. But this move is hard to follow, since it does not fit our usual ways of thinking. In the nature lectures, MerleauPonty eventually finds a clue to it in the "organism [which] is not only its localinstantaneous reality," "nor moreover [is it] another reality" (something "metaspatial”), rather it is a "macroscopic "envelopephenomenon'" that is not reducible to given elements but is "rather between the elements” ( $L N$ 275/213), which is to say it is "transspatial." 29

To make sense of Merleau-Ponty's point here, I first refer to his discussion of the embryology of Hans Driesch. Driesch discovered that (within limits), remarkably, animal embryos develop in typical ways even if they are, say, divided in two, or if patches of their surface are displaced from one position to another. In technical terms, embryos can robustly "regulate" growth in face of perturbations. In an analysis that amounts to a spatial echo of his typical dialectic with empiricism and rationalism, Merleau-Ponty argues that regulation cannot be rooted in either material atoms (the sort of "local-instantaneous reality" just mentioned above) or in something ideal ("another reality," "something metaspatial”). Basically, if the body plan is localized in atomic parts, then moving parts around would disrupt the plan-which is not what happens. Drietsch therefore appeals to an "entelechy" ontologically beyond the parts. But this leaves the problem of accounting for the reality of such an entelechy and giving an account of how it could, as beyond the parts, determinately respond to, or coordinate with, the embryo-body so that growth can be regulated in face of perturbation. (Note that ontological localism is the tacit premise of these rejected alternatives. ${ }^{30}$ Note also that the problem here is cognate to that of classic Cartesian dualism: if mind must be ontologically beyond the body to do the job that it does, then we cannot account for the internal coordination between mind and bodywhich is in fact crucial to the job of mind.) Merleau-Ponty thus pursues a determinacy that arises within the embryo itself (not in something metaspatial) without yet being purely local to atomic points: a determinacy that is "rather between the elements," something that is "transspatial," an “envelope-phenomenon” ( $L N$ 275/213).

To make sense of this transspatiality, I develop below a new concept, intensive sweep, or sweep for short, to capture a determinacy that arises in the ways that regions sweep into one another via their 'spread-dynamic.' I develop this concept, and thence Merleau-Ponty's concept of transspatiality, by discussing a recent claim by Rohlf and Bornholdt ${ }^{31}$ about the hydraa claim that makes Merleau-Ponty look prescient in seeking the embryo's determinacy in a transspatial relation.

The hydra, a microscopic animal, has what is called a bud zone, from which it buds offspring. This zone is (nearly) always two thirds of the way down the hydra's body. How is the bud zone positioned precisely at this point? We cannot say it is because of a special bud cell found two thirds of the way down, for this begs the question of why it is found there and not elsewhere. Moreover, we would need to say how this cell tracks the growth of the hydra, for its position is regulatory: the bud zone's position remains near invariant, two thirds down the body, through changes of hydra size over a tenfold range. Can we say that the hydra's genes are an idealized blueprint that, as it were, looks down on the hydra body and specifies that the bud zone is to be two thirds down the hydra, whatever its size? But this begs the question, broached above, of how the blueprint and body are coordinated. In any case this image of a 
blueprint whose determinacy is separable from the body, biologically speaking, is mythical. The hydra's genetic material is crucial to determining the bud zone, but not as an abstract blueprint. In concrete biological terms, we find complex genetic dynamics ${ }^{32}$ inside each cell of the growing body, in which: multiple segments of the genetic material are transcribed so as to produce proteins, or to dynamically regulate the transcription of other genetic segments; and in which this dynamic is modulated by other materials and dynamics of the cell, including genetic signals travelling between cells. ${ }^{33}$ This dynamic distributes genetic signals along the hydra such that there is a "rather graded decay" of "CN-NK2 expression" in the "budding region," while "Hedgehog (Hh) is turned off precisely just below the budding region" (Rohlf and Bornholdt, 178).

This distribution of genetic signals within the body determines part placement. The question is: what determines this distribution? Is it something local to each point, or a pattern that could be determined in abstraction from the points? The answer likely is something in between. Rohlf and Bornoldt show that in principle a process kin to the operation of a cellular automaton could produce the distribution. They simulate a line of cells that are linked by a complex network of interactions, in which:

(1) within a given cell $i$, genes G1 and G2 interact in such a way that

(2) this interaction is modulated by receptors in the cell membrane of $i$ that are responsive to the results of $\mathrm{G} 1 / \mathrm{G} 2$ interactions in the immediately neighboring cells $i-1$ and $i+1$, and

(3) this interaction in turn modulates receptors that modulate $\mathrm{G} 1 / \mathrm{G} 2$ interactions in those neighboring cells $i-1$ and $i+1$.

In their simulation, gene expression is robustly regulated such that a sharp division in the expression pattern always occurs two thirds of the way down the line of cells.

While Rohlf and Bornholdt's result is merely theoretical (their work is in theoretical biology), the principles at work in it correspond to real principles of embryogenesis, for example: heterotopy, the principle that divergences in morphology of different organisms often have to do with changes in the spatiotemporal regulation of the expression of a basic toolkit of genes shared by different organisms, versus differences in the basic toolkit; that is, divergence is by way of rendering places different in the organism, rather than producing different materials; and mosaic pleiotropy, the principle that very often a given protein expressed in the growing embryo works in many different ways in different places in the organism. ${ }^{34}$ Internal division of the embryo into different regions is crucial to embryogenesis.

This leads to a conceptual point having to do with placed vs. transportable thinking. Returning to Rolhf and Bornholdt's model, notice how in themselves the cells that determine bud placement do not contain (strictly speaking) anything like a measure of where they are with respect to some overall plan of the hydra. For us, observing, we can say: this determinate concentration of gene products marks a point two thirds down the body. But concretely: the concentration of genetic signals has its determinacy and determinate function (of positioning the bud) in virtue of the adjacent cells that form its immediate region, as swept up in ever more encompassing regions - ultimately the region of the hydra body as a whole in exchange with its environment. ${ }^{35}$ It is in virtue of this sweep of interactions across regions that there is a genetic signal concentration that positions the bud zone. But the latter is thus inseparably internal to this sweep: the concentration is not determinate in terms of 
abstract measures from above (e.g., " $2 / 3$ of the way down”). Its function as determining the place of the hydra bud zone is inseparable from where it is, from the dynamic latitude opened by the spread of this 'where,' as the specific 'where' of a hydrabody-in-its-environment. It is thus a function of its narrow region as verging into broader regions. This is all the more the case when we shift from the simplified simulation to the living hydra. This animal phenomenon demands placed, not transportable, thinking.

Here I have introduced sweep as a technical term, proper to placed thinking, to designate interactions and relations that run through adjacent and nested regions and that thereby engender determinate differences across said regions. The determinacy engendered by such sweep is intensive, in Bergson's sense: the determinacies that contribute to the determinacy of an overall sweep cannot be separated from one another or put alongside one another; they are internal to one another and modify one another's determinacy in the way that one's childhood (for Bergson) is internal to and shapes the sense of one's life as an enduring, unfolding whole. This is in contrast to a classic example of an extensive determinacy or measure, namely a meter: dividing a meter stick in two gives you two half-meterlong segments that can be put alongside one another, and the division does not change the meter standard. In contrast, if divided halves of a hydra remained viable, each such hydra would engender its own endogenous standard, with the bud zone growing (as we put it, from the outside) two thirds down each. Contrast this with cutting the meter stick in half. When you do this, the rulings and markings on the stick do not change. So, on one piece, the point we call two thirds down would appear at the $33.3 \mathrm{~cm}$ mark (two thirds down between 0 and $50 \mathrm{~cm}$ ); on the other, this point would appear at the 83.3 cm mark (two thirds down between 50 and
$100 \mathrm{~cm}$ ). If the meter stick were like the hydra, then cutting it in two would, in contrast, yield a qualitative change two thirds of the way down each piece, via an overall change along the whole piece: all the 'markings' and 'rules' would change their intensity when you cut it in two.

To give a better sense of what I mean by sweep, let me speak of music. It is the sweep of the music, its internal rhythmic and harmonic modulations, that determine when a piece turns from (say) developing tensions to resolving them. The resolution's advent is properly measured not by a clock that always divvies up time the same way, independent of when things happen, but in terms endogenous to the flow of the music itself, which involves the intensity of the music's own temporality. If we distinguish lived temporality from scientific time, the classic Newtonian clock provides a peculiarly atemporal measure of time: the clock parcels out eternity in the same way, whenever you are, independent of your flowing temporality. But music resists such atemporal thinking, because its meter is precisely inseparable from the internal, intensive sweep of its temporality. Similarly, the point here is that the hydra, in the very regulation of its growth, resists what I have called transportable thinking: the way it places parts is precisely inseparable from the internal, intensive sweep of its regions.

The link between the temporal sweep of music and the regional sweep of the organism is likely no mere accident. Goethe calls architecture frozen music, and what we are seeing here is that the organism's 'architecture' is kin to frozen (genetic) music - something Goethe grasped at least implicitly in conceptualizing flowers as spatially depositing, along a growing stem, successive variations of the cotyledon. ${ }^{36}$ This link between temporal and regional sweep is something I am trying to capture by playing on "sweep" as at once a noun and a 
verb.

Animal body plans are not laid out and determined in an abstract space (even if we see them that way); rather they forge themselves from within the body region, by way of sweep, a transspatial modulation ranging across (and beyond) this region. The growth of the animal to type, then, is a matter not of positioning transportable parts, each in its right position, in an abstract space, but of growing an animal body as a region whose sweep differentiates, for the first time, nontransportable regions for growing (for example) a leg versus an antenna-in the way that a geographical region sweeps out nontransportable subregions for growing grapes versus fishing. And this differential sweep is not due to a map of locative positions applied to the region from above, but due to a power of differences that develop by way of tensions that endogenously sweep across regions and their content. This means that in animal being, place - and a kind of power that place harbors-matters over space as neutral container.

What I am articulating here is something that Merleau-Ponty is noticing as central to being. For example, in the third nature lecture, his analysis of Driesch's embryology leads him to reject the alternatives of either local-instantaneous or metaspatial realities as the source of the embryo's developing determinacy and to conceptualize this determinacy as arising through "transspatial" relations, in virtue of which what I call regions already "envelop" one another. The phenomenon of life testifies against "a hard nucleus of being" (against localizable, corpuscular being) and for the "softness of the flesh." We must, he writes, "[d]issociate our idea of Being from that of a thing: life is not a separable thing, but an investment, a singular point, a hollow in Being, an invariant ontological relief, a transverse rather than longitudinal causality telescoping the other" ( $L N 302 / 238$ ). Life emerges internal to being, and not (merely) by a longitudinal generativity of time but by what I would call a transverse sweep of regions sweeping/telescoping over one another. This echoes an ontological point in the passivity lectures (articulated via Husserl, but in a long analysis departing from Ruyer's biology) that the thing "is absolute plenitude only in the face of isolating analysis" and even so "it is a hollow plenitude: presence but absence" (IP 174). In turn, these resonate with a point in a complex analysis of Bergson's critique of the negative and nothingness, in which Merleau-Ponty criticizes Bergson for in fact having a positivism in which "the absence of a thing" is "only the presence of something else" and argues that we must conceive "one sole Being that has an absolute negativity in its flesh" ( $L N$ 96/65). This takes us back to a point following our first quote from $L N$ immediately above, that "life is not negativity," by which he means, that lifeand the being of life-is not a positively given, already fixed, transportable negative, rather it is "field, dimension . . . depth for flat beings" (LN 302/238). ${ }^{37}$ I take it that Merleau-Ponty is saying there is an internal depth or latitude, a "softness" of being, in virtue of transverse, trans-spatial (vs. merely longitudinal, transtemporal) relations opened by being. This soft hollow allows for the engendering of determinacy, not by a given negativity, but by a not, a negative, that is not-yet-where this not yet is transspatially sweeping in character, in contrast to the notyet of Derrida's différance.

But this ontological point, about a spatialtype hollow of being, is hard to grasp. And this, I think, is because we are, by virtue of the particularities of our kind of animal being, better geared to transportable thinking than placed thinking. As well, the sort of cognitive ability that Descartes detects better tunes us to temporal not-yetness than 
transspatial not-yetness. So I now want to give further insight into the ontological point about sweep by exploring this difference between us and other animals. I show how we tend to navigate by way of idealized spatial blueprints, while other animals tend to navigate from within the intensive sweep of regions - so that we have mostly lost our sense of the sweeping power of place.

\section{Following Loggerhead Sea-Turtles into Place}

All animals depend on the places they inhabit to provide food and suitable conditions for producing and raising offspring. But a habitat suitable for rearing offspring is not necessarily suitable for feeding, or this suitability may vary with the seasons. Hence animals often need to exploit "widely separated habitats at different times of their lives," 38 that is, migrate. Instead of migrating, for the most part we human animals instead learn how to forge dwellings, technologies, and economies that render us relatively insensitive to climate and location. We bring what we need to us, instituting a style of living that is likely coeval with transportable thinking: where you are does not matter very much when you can live most anywhere.

In contrast, consider loggerhead sea turtles (Caretta caretta), which hatch in one sort of habitat but need to move to other habitats to find food for growth, which habitats are not suitable for nesting and hatching. How do adults find a habitat suitable for hatching the next generation? Loggerheads have evolved a simple solution: returning to their exact place of birth, across thousands of kilometres of sea (which other sea, land, and air species do as well). A contrast between the placed and the transportable is already at work here: a loggerhead does not search for a sort of habitat suitable for hatching, wherever that might be; it searches for just this one place, which is not transportable.

How does the loggerhead accomplish such a navigational feat? I focus on loggerheads, despite the fact that navigation in land- and air- (vs. sea-) nonhuman animals is better understood, because it enables a comparison with some remarkable studies of human sea navigation-and because the sea's unique "sensory ecology" presents special navigational problems that bring crucial points to light. ${ }^{39}$ Basically, the latter problems are due to water's density. While water carries scents better than does air, and wind-driven waves propagating in seasonally constant directions can provide navigational cues, water absorbs and scatters light in such a way that "[v]isual landmarks are absent" and "celestial cues" are rarely perceptible; moreover, animals in water are "continuously susceptible to ... currents" yet lack the sort of visual references against which wind-blown birds can correct drift. ${ }^{40}$

Scientists argue that sea animals navigating this problem need two sense faculties. First, a "map sense" that "enables the animal to determine its position relative to the goal (or at least the direction in which it should travel [from where it is])"-a sense that positions the target and animal relative to one another. Second, a "compass sense," "used to maintain a heading in the appropriate direction” once the target position is established. ${ }^{41}$

Lohmann and his colleagues hypothesize that the loggerhead's map sense has a magnetic basis. Imagine the earth's magnetic field lines as narrow ribbons. At the magnetic equator, these run in a shallow ' $S$ ' curve relative to the geographical equator, and the surface of the 'ribbon' is parallel to the earth's surface. As one moves north, the surface of these ribbons inclines more toward the earth's surface, and conversely for moving south. Field lines also vary in intensity, independent of inclination. A line traced through places 
with the same magnetic inclination is an isoclinic, one traced through places with the same magnetic intensity is an isodynamic. Isoclinics and isodynamics (collectively called isolines) do not exactly line up, but describe a drapery of overlapping scalloped curves, such that a combination of a given isoclinic and isodynamic can roughly identify a particular region. The hypothesis is that sea turtles imprint on the isoclinic and isodynamic of their birthplace. To return to it, they either first navigate 'by compass' such that they hit a coastline, and then move up or down the coast until they sense the isolines on which they were imprinted; alternately, they might navigate at sea to find their isoline, and then follow it into the coast. After this first phase of navigation, once near their birth region, the turtles enter a second phase of navigation in which other cues (isolines are too rough) could guide the turtle to its birth-beach. Lab and field experiments support the first part of this "biphasic" hypothesis by showing that loggerheads do in fact orient to magnetic fields. For example, captured older turtles, exposed to (experimentally produced) magnetic fields that would exist $340 \mathrm{~km} \mathrm{~N}$ or S of their capture site, "swam in directions that would have led them home had they actually been displaced to the locations where the two fields exist." 42

Drawing on our discussion above, we can say that the loggerhead is sensitive to the intensive sweep of regions, as manifest in magnetic variations sedimented in the earth by its intensive geological formation ${ }^{43}$ (in something of an analogy to the sweep of genetic signals sedimented in the growth of the hydra body). Biologists conceptualize bees and flowers as co-evolving: the color of flowers is 'selected' to attract beepollinators, and bee vision is 'selected' to be sensitive to flower-colors that sweep out food regions. The point here is that loggerheads have evolved sensitivity to an existing magnetic sweep of the earth. But this means that the loggerhead and its lifecycle is a function of the magnetic sweep of the regions it inhabits. While the loggerhead of course moves around from region to region, it is not properly speaking a 'transportable animal': it cannot get around in loggerheadly-living ways in any old place, just this one. Indeed, the above hypothesis depends on the regional contingency that the coasts on which loggerheads hatch happen to run mostly N$\mathrm{S}$, while isolines run $\mathrm{E}-\mathrm{W}$ - which lets isolines differentiate coasts into different regions.

The loggerhead is oriented by the sweep of its region, and so has a very different, interior, intensive relation to place than we humans typically do, as (relatively) transportable animals who can live most anywhere and tend to get around by extensively dividing up space as appropriate to different tasks. Here we once again run into a subtle and difficult conceptual point at stake in the difference between placed and transportable thinking. The point could perhaps be drawn out by way of MerleauPonty's remarks on the spatiality of animals such as the jellyfish, the chimpanzee, and the human. But I want, instead, to tackle the conceptual issue by availing myself of two recent results. (We are also approaching here points arising in discussions of Heidegger's contrast between Dasein's being-in, things as in containers, and animals as captivated by their environment, as well as issues in Deleuze- - but in a different and more fine-grained way.) ${ }^{44}$

The first is Colin Ellard's synthesis of studies of the psychology of navigation, in Where Am I? Why We Can Find Our Way to the Moon But Get Lost in the Mall. ${ }^{45}$

Throughout, Ellard flags a remarkable fact: we humans are easily lost, whereas it is quite the opposite with other animals. Indeed, Ellard writes that some experiments 
"require that animals lose all sense of spatial connection with the world outside the walls of the testing room" to ensure that "the behaviour of the animals is under the complete control of cues present in the room"; yet it can be so "extraordinarily difficult to produce that state of spatial detachment in an animal" that in Ellard's laboratory, "animals are sometimes conveyed from one place to another inside a light-free container that is rotated on a turntable en route to the testing room"otherwise the animal will show signs of not being lost. In contrast, humans are so bad at navigating that Ellard's problem is not getting them lost but, for example, providing them "with enough support that they can find their way [blindfolded] across an ordinary rectangular room without banging their heads into the walls" (73-75).

What is the basis of this difference between human animals and other animals? Let me condense Ellard's detailed survey into a twofold point. First, on a sensorymotor level, humans have (or typically cultivate) very different capacities, abilities, and skills from those of most other animals: our sensing and moving ability is usually much coarser. Second, we navigate by way of abstract symbols or maps, as if looking down on ourselves from above, as if the task is transporting ourselves according to a space that maps onto our surroundings, rather than being tuned to the sweep of regions we inhabit as already determinately positioning us. There is a convergence here between Ellard's psychological point and Merleau-Ponty's notion of the pensée survole, which both inform my concept of transportable thinking. We could think of this second feature-navigation by abstract concepts - as a compensatory strategy for our weak sensory-motor ability, or conversely, we could think of our tendency to navigate by abstraction as enabling sensory-motor inattention. Either way, to put it in a nutshell, we are generally inobservant and inclined to abstraction, or, more precisely: we observe abstractions rather than sensuous detail. Suppose we present various animals with a cache in the centre of a square defined by four landmarks and then increase the square's size. Rats or gerbils "will search [for the cache] in a series of four different locations," each "the same distance and direction from the landmark as before the change," whereas humans "continue to search in the centre of the square as defined by the four landmarks"we search by way of the abstraction "center" (43-44). We are easily lost in the forest because we see trees $\mathrm{X}, \mathrm{Y}$, and $\mathrm{Z}$ not as three singular, unique, individuals but as three instances of tree-in-general. Overall, Ellard notes that "psychological tendencies that have their roots in the orientation of our body and the organization of our senses seem to have taken precedence over what we see and feel of the dimensions of physical space," such that we "construct spaces rather than sense them" (123).

My claim is that it is because we construct extensive spaces, rather than sense the intensive sweep of regions, that we are inclined to transportable rather than placed thinking. To navigate, we humans cultivate mutually reinforcing ways of observing and conceptualizing our reality; and the ways typically cultivated by the Western tradition blind us to the power of place, by inclining us to conceptualize space as a fixed, neutral system, rather than to sense our surroundings as a region with its own intensive dynamic.

This becomes apparent through our second result, a remarkably insightful and detailed study of human sea navigation practices in Edwin Hutchins' Cognition in the Wild. Hutchins's aim is to show that traditional Western navigation practice (his focus is American naval ships piloting into port) depends on the embodiment of 
cognitive/computational processes in the instruments, charts, and interaction of the navigators. But on the way he draws a conceptually insightful distinction between Western and Micronesian navigation practices (especially in Puluwat).

Crucially, Hutchins does not conceptualize Western practice as superior to the Puluwatan or vice versa: they are different solutions to a single, underlying computational problem, namely, detecting environmental features that specify constraints on one's position (e.g., "I am somewhere on this heading”) and combining constraints to uniquely fix one's position. Basically, the Western solution is to do most of the computation in advance. Charts embody complex computations: drawing lines on them and/or measuring them lets you calculate either your distance or direction to your destination (depending on the chart's projection type); the intersection of lines computes where you are. The Western navigator's main task is observing features in the real world via devices (e.g., compasses, or sighting devices that display the angle between a landmark and the vessel) that output numbers that embody computations that allow coordination of the chart with real world position. This enables drawing lines on the chart that compute where you are.

This navigation practice, I suggest, is complementary to or coeval with Cartesian dualism. First, the task is coordinating (via latitude and longitude coordinates) the bodily place you are in with a representational space that is different from place, in being clear and distinct, abstract, mathematized, ready-made. Second, provided with the charts, tools, and skills, the navigator can pull this off no matter where she is. Third, to navigate this way is thence to first locate oneself as a transportable, universal subject via a pensée survole that reduces one's body to a coordinate that coordinates with a transportable, Cartesian space that is navigation's real concern. For a culture to solve the problem of navigation this way, it must already (or eventually needs to) be prepared to think of bodies and space in a transportable and disembodied manner. (Yet even in this mode of navigation, abstract space still needs to be coordinated with bodily place-but on the extensive terms of a ready-made space that can be assigned coordinates in advance.)

In contrast, Puluwatan navigation depends on what Hutchins calls a "situated seeing" attuned to what I have called the intensive sweep of regions. This entails a very different concept of place. ${ }^{46}$ Put in Hutchins's framework, the Puluwatan learns to see the world itself as solving the computational problem. On the long range, Puluwatan navigators learn to see the circling stars as a compass, and they memorize the relative locations of islands according to this compass. To head from island A to B, for example, one sets out for $\mathrm{B}$ by heading in the direction indicated by a circle of stars that, over the night, successively rise or set at the horizon in a way that invariantly marks determinate earthly directions. To navigate by star compass, Puluwatan navigators also need to adjust their initial heading to compensate for (seasonably variable) prevailing winds and currents - which again must be memorized. And they have to be incredibly sensitive to and knowledgeable of prevailing swells, wave action, wind, and so on, to keep the sailing canoe on heading. To home in on a destination island, once in its rough vicinity, navigators orient by a more fine-grained situated perception, tuned, for example, to changes in wave patterns due to interference from islands, changes in water color or smell due to underwater sea mounts or biogeographical features, changes in sky color above islands due to reflectance from 
islands, or changes in sea life, such as the presence of certain fish or birds that move in relation to islands in species-specific ways.

Several things are of note here. First, such navigation is immersed in the intensive sweep of things: the task is to see how regions compute one's position through their endogenous differences. Second, the sweep through which one navigates is not transportable or abstractable. A Western navigator at any arbitrary coordinate $\mathrm{X}$ (given the charts and apparatus) can, in principle, navigate to any other arbitrary coordinate Y. As locative positions, all such coordinates are interchangeable; and where you are does not matter to your ability to navigate to $\mathrm{Y}$, since your locative position is a coordinate in an abstract space whose extensive measures are globally invariant. (But even in this practice, local knowledge can be important, especially in pilotage to port-although perhaps this is becoming less important with GPS systems.) In contrast, on routes between islands, the Puluwatan navigates by learning to perceive cues endogenous to specific regions. Indeed, the navigational efficacy of the star compass is contingent on the islands visited being distributed more on an E-W than N-S axis, and being in a narrow band near the equator. Moreover, knowing how to sail from island A to $\mathrm{B}$, and from $\mathrm{B}$ to $\mathrm{C}$, will not necessarily enable sailing directly from $C$ back to $A$ - or from A to $C$. This seems very strange if we conceptualize navigation as transporting oneself around in an abstract space, for travelling from $\mathrm{A}$ to $\mathrm{C}$ via $\mathrm{B}$ would entail knowing where $\mathrm{A}$ and $\mathrm{C}$ are-knowing their coordinates - and once one knows that, one can navigate from $\mathrm{C}$ to $\mathrm{A}$.

This precisely emphasizes that the Puluwatan does not navigate an abstract space. He knows where islands are not by abstract locative coordinates, such that the determinate position of A can, as it were, be transported with the Puluwatan from B to C, with A's location remaining what it is independent of where the navigator is. Rather, the Puluwatan senses a regional positioning of islands from within the intensive sweep of island regions themselves.

This is most emphatic when we attend to the Puluwatan way of conceptualizing progress to destination, which is called etak. To navigate from island A to B by star compass, you need to know your position relative to $\mathrm{B}$, so you can start homing in when near it. It is not surprising that Puluwatan navigators sense this position via intensive sweep, not abstract, extensive measures from above. Imagine walking eastward from A to B along a long E-W street. An office tower, C, far to the north of the midpoint of $\mathrm{AB}$, will appear to drift back along the horizon as you approach B: at A, the direction from you to $\mathrm{C}$ is $\mathrm{NE}$; at the midpoint it is N; at B it is NW. Puluwatans similarly sense their position by conceptualizing a distant reference island (sometimes imaginary), invisible over the horizon, drifting back under different star bearings, in a line along the horizon. Here a subtle and difficult conceptual point comes into play. The point is difficult precisely because, Hutchins argues, we Westerners (including other scholars whose position he is contesting) automatically conceive etak as a way of measuring distance along an already described line $A$ and $B$, via the triangle that A-B forms with $\mathrm{C}$. That is, we conceptualize navigation by etak as if we are looking at it from above: we plot various positions $\mathrm{P}_{1}, \mathrm{P}_{2}$, on $\mathrm{A}-\mathrm{B}$, draw lines from each $\mathrm{P}_{\mathrm{n}}$ to $\mathrm{C}$, and notice that the changing direction from $\mathrm{P}_{\mathrm{n}}$ to $\mathrm{C}$ in $a$ space already given corresponds to and thus measures given segments of A-B. But Hutchins persuasively argues that this misrepresents Puluwatan concepts and experience. First, in general, a Puluwatan conceptualizes and experiences his canoe as 
stationary, with water and islands moving toward and past it. Gladwin has a very compelling description of this experience, which resonates with Husserl's ${ }^{47}$ discussion of the ship moving between the stars being stationary for the explorers, and Thor Heyerdahl's report of this sort of experience in his long voyage on the raft Kon-Tiki. Second, Puluwatans also experience the reference island as moving. Third, Hutchins cites Lewis' report of an exchange with a master navigator, Hipour. Lewis was trying to locate an island, Ngatik. Hipour knew the star bearings to sail to Ngatik from Oroluk and from Ponape. But when Lewis located Oroluk and Ponape on a map, and then used the star bearings from these two islands to triangulate to where Ngatik must be, Hipour failed to grasp the idea behind this. Hipour could only grasp the idea by imagining himself to be simultaneously (1) sailing from Oroluk to Ponape and (2) sailing the reverse voyage-and picturing the etak bearings to Ngatik from within the beginnings of both voyages. Hutchins argues this is because Hipour is not navigating, as Westerners do, via "a global representation of the locations of various pieces of land relative to each other" as seen from a "bird's-eye" view. For Hipour, the star bearing of an island "is not simply the orientation of a line in space but the direction of a star point from the position of a navigator"-it is not a transportable bearing. You have to be in the region where the bearing is taken for it to make sense, and bearings do not make sense as lines in an abstractly given space (which would enable Lewis' triangulation procedure) but as ways of modulating the moving sweep of regions.

Again, it must be emphasized that in voyaging through regions, the Puluwatan experiences stars and islands as moving around, relative to one another, in a characteristic pattern-rather than experiencing himself as moving through a fixed layout. It is this moving pattern that sweeps out a determinate texture of a region — and that enables positioning of islands in it. As with the hydra body, we do not first have an abstract, blank space, and then the locating of points in it: what we first of all have is a movement that sweeps out differences.

Altogether, as I understand Hutchins, his point is this: The Western navigator positions herself by way of bringing together two different constraints (e.g.: bearing and distance to target; or two bearings to two targets, which triangulate one's position) that locate her in a space grasped from above - what I called locative positioning. The Puluwatan positions himself by way of two constraints, but they are rather different: they are not constraints in an abstract space, but sensuously endogenous to a region. One constraint is the heading toward the target island. This is experienced in keeping the canoe on the track of a circle of stars in the star compass. The second is etak. This is experienced as the movement of the reference island along the horizon, which horizon is experienced as running parallel to one's heading. Think back to my example of walking from A to B: to navigate this course, you stick to the street straight ahead, and see the destination nearing in the movement of the tower $\mathrm{C}$ sliding back in a line alongside you. Or think of the like phenomenon in various different train journeys, where you see a distant mountain sliding back in a rate/rhythm that characterizes the arc of the journey. The relative rhythms/rates of your straight course and the sliding of the reference point gives you a sense of your regional progress and position-but does so in terms of intensive sweeps endogenous to your movement through the region (if you do not convert this into a view from above). That is, we might think that the Puluwatan's experience of journeying from $\mathrm{A}$ to $\mathrm{B}$ and nearing the 
end of the trip is cognate, in experiential structure, to sensing an unfolding piece of music come to its close. The difference is that the resolution criteria of the journey need to be learned and memorized (rather than instituted by musical practice), since they are endogenous to the various different regions travelled through and the way islands work together. So we could say that the Puluwatan memorizes and learns to see a kind of music, or better, dance, of regions that engenders a determinacy of subregions. This dance of regions is what I am getting at by intensive sweep-and what we Westerners, Cartesian geometers - and Cartesians-typically fail to notice.

This is also, on first glance, the sort of thing to which loggerheads evolve physiological sensitivity. But it would be a tremendous mistake to think that Puluwatan navigation practice, insofar as it is cognate to the loggerhead biphasic strategy and is attuned to the intensive sweep of regions, is 'more animal' than the Western practice. That would entirely neglect the fact that Puluwatan navigation is a cultural product that entails developing knowledge and conceptual systems and drawing on general capacities of human bodies to cultivate highly sensitive observational abilities. The Puluwatan and Western navigation practices are two different ways of compensating for the fact that human animals are easily lost and do not have inborn sensitivity to the sweep of regions. If the Puluwatan and loggerhead strategies are cognate, it is because both are navigating a similar problem. The navigational practice of the Puluwatans constructs a way into the sort of intensive sweep of regions to which loggerheads have evolved sensitivity, while Westerners construct an extensive space in which to navigate - although, as Hutchins notes, before the invention of the compass Western navigation looked much more like the star and place oriented practice of
Puluwatans. Nonetheless, because Puluwatan culture tunes navigators to intensive sweep, it gives us an insight into an ontology in which space is not corpuscular and concrete, but intensive, dynamic, enveloping, transspatial—and hollow. For what the Puluwatan experiences are regions as determined by the relative dancing slippage and movement of islands, stars, and bodies relative to and in virtue of one another's mutual envelopment. This sort of slippage is implicitly leveraged in the hydra's growth as differentiating regions that place parts.

\section{Conclusion}

We thus circle back to the conceptual juncture between animal being, the being of place, the being of diversity, and the difference between the human animal and other animals.

First, via study of loggerhead and human animal navigation, we see that determinate movement on this planet entails encountering the being of place as having its own intensive dynamic, its own way of sweeping out regions. We do not usually notice this because we tend to a transportable thinking that immediately reduces the intensity of regional sweep to the extensity of an abstract space of locations mapped from above. But in the examples of the loggerhead and hydra, we find cases in which positioning the animal self or its parts involves a moving modulation through the intensive sweep of regions, something spatially cognate to a musician finding her way to the end of the piece, not by knowing from the beginning at what time or on what note it is going to end, but by feeling a resolution grow and coil from within the music's flow. That the determinacy of regions involves this 'music,' or better, 'dance' of sweep becomes express in the Puluwatan experience of 
navigation, on my understanding of it.

Second, this sort of determinacy entails an opening, a latitude for movement, in the interrelation of regions that allows an intensive power to sweep across regions and differentiate them. This is what we noticed as crucial to placing parts in the hydra body. Here we should notice that, on a geological time scale, islands do in fact drift relative to one another. Conceptualizing them as fixed in space entails a certain temporal perspective. The astronaut navigating between circling planets cannot easily conceptualize planets as fixed this way. It is also the case that experiencing islands as fixed requires a spatial perspective, namely, a view from above. This view is crucial to the Western navigation strategy. But this view from above still needs to be coordinated with experienced place as intensively modulating itself: that's where the work of Western navigation happens. So, the Western navigation practice does not rid place of its intensity but, rather, fails to see it as and for what it is. But noticing this educates us into a conceptual blind spot: we cannot see that the being of place has a power to it, a non-givenness or dynamic, that is as powerful, non-given, or dynamic as the power we find-and that phenomenology detects-in temporality as not-yetgiven.

I maintain that it is this spatial-type notyet-givenness, and its power to generate sense, that Merleau-Ponty is broaching when he speaks of a hollow or negative in being that is crucial to the sense we find, for example, in the growth of animal bodies. To put it another way, above I distinguished ontological localism, which seeks to conceptualize the determinacy of things as localizable in arbitrarily small points, and ontological regionalism, which sees determinacy as always being a function of horizonally nested regions. The thought here is that the determinacy of being itself is ontologically regional, a function of dynamically changing sweeps across place (as well as temporality), rather than being something that could be given or rest in discrete locations within being. With Collingwood, we could say that being takes a minimum of space to be. But - and this is the difficult point - this is not a minimum of some already given space, it is a minimum of region engendered in the very being of being. Bergson would teach us that we have to wait for being to happen determinately, or better, that being has to wait to be. The thought here is something like: being has to wander to be. Becoming ander, wonder, questioning, and so on, have regional roots. And the condition of being wandering is being hollow, having endogenous latitude to wander.

Third, we have found here various affinities between humans and other animals. We animals are all in the same boat, we all need to move, but we move our boats in different ways. Other nonhuman animals tend to have bodies and sensoria that, in whatever way, gear them finely to the sweep of regions. We humans, on the other hand, are weakly tuned to the determinacies of place and compensate by either cultivating memory of and sensitivity to regional intensities or, as it were, detaching ourselves from the overwhelming intensity of places to construct an ideal space amenable to what we are good at navigating. We have often distinguished ourselves from other animals by proclaiming ourselves the rational animal, and so on. In this way we conceptualize this difference as rooted in a capacity that is not animal at all-for example, in Cartesian mind as irreducible to animal body. Here we are going quite the other way: what describes our differences and continuities with other animals precisely springs from our animal capacity as weak. Our animal weakness, our being lost, inclines us to tell stories about 
how to get from here to there and to transmit them to our children or to invent abstractions that bypass this sort of weakness. If we can think that we are Cartesians, this is in fact because we are lost animals who have become Cartesians in order not to be lost. The Cartesian does not spring from a mind most unanimal; it is rather our way of being animal that generates Cartesian mind as a retrospective illusion. And our way of being animal need not lead merely in that direction; it can lead to quite a different kind of attunement to our surroundings.

In other words, as Merleau-Ponty would put it, we are different from other animals precisely by way of our "strange kinship" with them. ${ }^{48}$ Attending to this kinship, as I have hoped to have shown can give us a different sense of our being, animal being, and the place of being itself.

\footnotetext{
${ }^{1}$ I would like to thank Noah Moss Brender, Shiloh Yadah Whitney, Don Beith, and Tristana Martin Rubio for their insightful comments and suggestions on this paper and acknowledge the inspiration derived from our ongoing studies together and from their papers on Merleau-Ponty on: chimpanzee spatiality (Moss Brender); perspective drawing as institution (Whitney); and Earth as origin (Beith).

${ }^{2}$ See note 29.

${ }^{3}$ As Ted Toadvine rightly urges in Merleau-Ponty's Philosophy of Nature (Evanston, IL: Northwestern University Press, 2009), across his career MerleauPonty's various challenges to reductive dualisms of mind/body, human/animal, human/nature, entail showing how nature already has a sense in advance of our thinking. In his brief chapter on space, Toadvine suggests how, for Merleau-Ponty, this sense stems from space and involves a space that has its own endogenous sense.
}

My project ends up digging into details that complement his point. In urging that Merleau-Ponty's career is unified by an effort to ever more locate the roots of sense in nature, which is to say, in being as given in advance of thinking, both Toadvine and I are, I think, following the general tendency of, for example, Renaud Barbaras, "Perception and Movement: The End of the Metaphysical Approach,” in Chiasms: Merleau-Ponty's Notion of Flesh, ed. F. Evans and L. Lawlor (Albany: State University of New York Press, 2000); “The Movement of the Living as the Originary Foundation of Perceptual Intentionality," in Naturalizing Phenomenology: Issues in Contemporary Phenomenology and Cognitive Science, ed. J. Petitot, F. J. Varela, B. Pachoud, and J.M. Roy (Stanford: Stanford University Press, 1999); The Being of the Phenomenon, trans

T. Toadvine and L. Lawlor (Bloomington: Indiana University Press, 2004); and "Merleau-Ponty and Nature," Research in Phenomenology 31 (2001): 22-38.

${ }^{4}$ For an illuminating introduction to this difficult topic, see John Sallis, "Grounders of the Abyss," in Companion to Heidegger's Contributions to Philosophy, ed. C. E. Scott (Bloomington: Indiana University Press, 2001). There is no room here to even begin tracing the differences between MerleauPonty and Heidegger on this ontological issue, or the ways that nonhuman animals figure in it.

${ }^{5}$ This tendency would also be related to a tendency of our tradition to privilege time over space, see Edward S. Casey, Getting Back into Place: Toward a Renewed Understanding of the Place-World (Bloomington: Indiana University Press, 1993).

${ }^{6}$ Here inspiration comes from Casey, who would remind us of resonances with 
Aristotle deep in the background. See his Getting Back into Place; The Fate of Place: A Philosophical History (Berkeley: University of California Press, 1997); and Remembering: A Phenomenological Study, 2nd ed. (Bloomington: Indiana University Press, 2000).

${ }^{7}$ On the logic of this strange kinship, see Ted Toadvine, “ 'Strange Kinship': Merleau-Ponty on the Human-Animal Relation," in Phenomenology of Life-From the Animal Soul to the Human Mind, Book I: In Search of Experience, ed. A.-T. Tymieniecka (Dordrecht: Springer, 2006) and Merleau-Ponty's Philosophy of Nature, esp. chap. 3. The notion that our difference from other animals might be conceptualized in terms of a weakness, an animal inability correlative to our flexibility, has been explored by drawing an interesting connection between Heidegger and Plato's Protagoras, in Rafael Winkler, "Heidegger and the Question of Man's Poverty in World,” International Journal of Philosophical Studies 15, no. 4 (2007): 52139.

${ }^{8}$ Here I am not quite following Jacques Derrida, "The Animal That Therefore I Am (More to Follow)," Critical Inquiry (2002): 369-418.

${ }^{9}$ The lectures on nature are cited as $L N$ with reference first to French then to English page numbers: Maurice Merleau-Ponty, La nature: notes, cours du Collège de France (Paris: Seuil, 1995); translated by R. Vallier as Nature: Course Notes from the Collège de France (Evanston, IL: Northwestern University Press, 2003). The lectures on institution and passivity are cited as $I P$, followed by French page numbers: MerleauPonty, L'institution, la passivité: Notes de cours au Collège de France (1954-1955) (Paris: Editions Belin, 2003); translated by L. Lawlor and
H. Massey as Institution in Personal and Public History and The Problem of Passivity: Sleep, the Unconscious, Memory: Course Notes at the Collège de France (1954-55) (Evanston, IL: Northwestern University Press, forthcoming); English translations are drawn from the latter, which includes the French pagination.

${ }^{10}$ See Toadvine, Merleau-Ponty's Philosophy of Nature, for a different discussion of MerleauPonty's method in relation to animals. Toadvine focuses on the problem of how Merleau-Ponty as phenomenologist can take animals seriously, given the view that phenomenology is concerned with experience, but our experience inherently excludes experience of the animal as such. Toadvine's solution is to emphasize how Merleau-Ponty, especially in his later work, reconfigures the human-animal relation. I take a different approach: I take phenomenology to be defined by studying the things themselves, with the aim of having the things shape our concepts, rather than fitting things into ready-made conceptual frameworks; and I take it to be unproblematic to say that phenomenology can study natural and animal phenomena in such a way as to lead to new conceptual results. I then show how results of this sort of phenomenology lead to a new view of the human-animal relation. To claim in advance that phenomenology cannot study animals or nature is to presume that the locus of phenomenology is some sort of experience that must be restricted to the subject. But this would presuppose the object of phenomenology. And from the start, I would argue, Merleau-Ponty is having us read our way into phenomena such as the experience of children and of people with different forms of experience; and he urges that the proper domain of phenomenology is not so much individualized experience as a phenomenal field that-as depending on 
“creative operations," the pre-personal, a past which has never been present-is already far beyond the local experience merely of a subject. This sort of shift becomes ever more emphatic in the passivity lectures: we are passive to something prior to experience. The method of radical reflection, as Toadvine notes, is an effort to take this into account within phenomenology.

${ }^{11}$ This displacement is echoed in, and is an underlying conceptual issue of, the passivity lectures.

${ }^{12}$ Sara Heinamaa, "From Decisions to Passions: Merleau-Ponty's Interpretation of Husserl's Reduction,” in Merleau-Ponty's Reading of Husserl, ed. T. Toadvine (Dordrecht: Kluwer, 2002), 127-46, provides another route to a link between method and passivity in Merleau-Ponty.

${ }^{13}$ Hence the emphasis in Toadvine, Merleau-Ponty's Philosophy of Nature, on Merleau-Ponty as seeking a sense already at work in nature. Schelling's system emphasizes that passivity is integral to intuition and that intuition is inseparable from nature; Husserl emphasizes both a passivity integral to synthesis and that we intuit rather than constitute essences. ${ }^{14}$ Maurice Merleau-Ponty, The Visible and the Invisible, trans. A. Lingis (Evanston, IL: Northwestern University Press, 1968). ${ }^{15}$ Merleau-Ponty, "Eye and Mind,” in The Primacy of Perception (Evanston, IL: Northwestern University Press, 1964), 162, quoting Valéry.

${ }^{16}$ This connection between nature and being raises an issue that cannot be addressed in full here. In brief, though, I take nature to be the visible of being. Merleau-Ponty is trying to read from this visible to its invisible. Being is visible nature together with its invisible.

${ }^{17}$ Henri Bergson, Matter and Memory, trans. N. M. Paul and W. S. Palmer (New
York: Zone Books, 1991) and Creative Evolution, trans. A. Mitchell (Mineola, NY: Dover, 1998). Martin Heidegger, Being and Time, trans. J. Macquarrie and E. Robinson (New York: Harper and Row, 1962). ${ }^{18}$ See especially the introduction to R. G. Collingwood, The Idea of Nature (London: Oxford University Press, 1945).

${ }^{19}$ Chukuka S. Enwemeka, "Inflammation, Cellularity, and Fibrillogenesis in

Regenerating Tendon: Implications for Tendon Rehabilitation,” Physical Therapy 69 (1989): 816-25.

${ }^{20}$ Elkhonon Goldberg, The Executive Brain: Frontal Lobes and the Civilized Mind (Oxford: Oxford University Press, 2001). Christine A. Skarda, Christine and Walter J. Freeman, "How Brains Make Chaos in Order to Make Sense of the World," Behavioral and Brain Sciences 10 (1987): 161-95.

${ }^{21}$ See page 199 below.

${ }^{22}$ This qualification restricts the point being argued, which is that absent things, space would not be a determinate system. The point is not quite about the being of space in the first place.

${ }^{23}$ Casey, Getting Back into Place and The Fate of Place.

${ }^{24}$ Jeff E. Malpas, Heidegger's Topology:

Being, Place, World (Cambridge, MA: MIT

Press, 2006) and Place and Experience: A

Philosophical Topography (Cambridge:

Cambridge University Press, 1999).

${ }^{25}$ Here and above, I am thinking of "dynamic" not as it might be defined in current physics, but I am going back to Aristotle's conception of dynamis as a kind of power of change of something.

${ }^{26}$ In drawing this sort of contrast, I am inspired by distinctions drawn by Casey in his various studies of place vs. space, but I am not quite drawing the same distinctions as he is, since the issues I am analyzing require different sorts of distinctions. I am 
also inspired by Casey's recent work on edges, borders, and boundaries.

27 This tension between space as absolute and transportable perhaps suggests an internal instability that calls for ontological regionalism; indeed, the arbitrariness of spatial origins and orientations is precisely at the core of Leibnitz's argument, in his letters to Clarke, against Newtonian absolute space.

${ }^{28}$ For a recent and very helpful survey of this issue, see Peter J. Bowler, "Geographical Distribution in the Origin of the Species," in The Cambridge Companion to the "Origin of Species," ed.

M. Ruse and R. J. Richards (Cambridge: Cambridge University Press, 2009).

${ }^{29}$ The theme of the transspatial appears at LN 37, 156, 165, 231, 233, 239, 279, 292, 298 / 18, 115, 122, 176, 178, 183, 217, 229, 235. It designates a way between the ontological opposition between atomic localism vs. metaspatial ideas. Often the word "transspatial" is associated with the "transtemporal" and is sometimes related to Whitehead's process philosophy.

${ }^{30}$ The appeal to local-instantaneous realities obviously involves ontological localism and transportable thinking, insofar as points are locally determined independent of where they are. So too does appeal to a metaspatial entelechy, insofar as its determinacy is supposed to be local to it (wherever it 'is'), independent of where shifting parts are, leaving the problem of coordinating the entelechy with shifting parts.

${ }^{31}$ Thimo Rohlf and Stefan Bornholdt, "Morphogenesis by Coupled Regulatory Networks: Reliable Control of Positional Information and Proportion Regulation," Journal of Theoretical Biology 261, no. 2 (2009): 176-93.

${ }^{32} \mathrm{I}$ am here drawing on a point in Evelyn Keller, "The Century Beyond the Gene," Journal of Biosciences 30, no. 1 (2005): 3-
10, that given the ambiguities and complexities of the concept "gene," we should perhaps talk about the organism's genetics, rather than genes, so as to keep in mind the overall complexity of genetic dynamics inside the organism.

${ }^{33}$ For studies of these sorts of processes in their relevance to development (and evolution) see, for example, Marc W. Kirschner and John C. Gerhart, The Plausibility of Life: Resolving Darwin's Dilemma (New Haven: Yale University Press, 2005) and Eric H. Davidson, The Regulatory Genome: Gene Regulatory Networks in Development and Evolution (Burlington, MA: Academic Press, 2006). ${ }^{34}$ For these principles, see Sean B. Carroll, "Evo-Devo and an Expanding Evolutionary Synthesis: A Genetic Theory of Morphological Evolution,” Cell 134, no. 1 (2008): 25-36, and Kirschner and Gerhart, The Plausibility of Life. Also see a special section on "Spatial Cell Biology," summarized in Stella Hurtley, "Location, Location, Location: Introduction to a Special Section on Spatial Cell Biology," Science 326 (2009): 1205, which, among other things, shows that similar principles are at work within cells. All together, this suggests that spatial processes that sweep out regions are crucial at many levels in biology.

${ }^{35}$ For the role of environment in development see Cor van der Weele, Images of Development: Environmental Causes in Ontogeny (Albany: State University of New York Press, 1999), and Scott F. Gilbert, "Ecological Developmental Biology: Developmental Biology Meets the Real World,” Developmental Biology 233, no. 1 (2001): 1-12.

${ }^{36}$ See Johann Wolfgang Goethe, Botanical Writings, trans. B. Mueller (Woodbridge, CT: Ox Bow Press, 1989).

${ }^{37}$ On these passages, also see David Morris, "The Time and Place of the Organism: 
MerleauPonty's Philosophy in Embryo," Alter: revue de phénoménologie 16 (2008): 69-86.

${ }^{38}$ Kenneth J. Lohmann, Nathan F. Putnam, and Catherine M. F. Lohmann, "Geomagnetic Imprinting: A Unifying Hypothesis of Long-Distance Natal Homing in Salmon and Sea Turtles," Proceedings of the National Academy of Sciences of the United States of America 19, no. 49 (2008): 19096-19101.

${ }^{39}$ It might have been better to study our mammalian kin, whales and dolphins, but there seems to be a dearth of literature on their ways of navigating - and it might be better to follow an animal a bit stranger to us.

${ }^{40}$ Kenneth J. Lohmann, Catherine M. F. Lohmann, and Courtney S. Endres, "The Sensory Ecology of Ocean Navigation,” Journal of Experimental Biology 211, no. 11 (2008): 1719-20.

${ }^{41}$ Ibid., 1720.

${ }^{42}$ Ibid., 1721. Also see Kenneth J. Lohmann, Catherine M. F. Lohmann, and Nathan F. Putnam, "Magnetic Maps in Animals: Nature's GPS,” Journal of Experimental Biology 210, no. 21 (2007): 3697-3705, and "Geomagnetic Imprinting: A Unifying Hypothesis of Long-Distance Natal Homing in Salmon and Sea Turtles," 19096-101.

${ }^{43}$ On the geological patterning of the earth as intensive, see Manuel Delanda, "Immanence and Transcendence in the Genesis of Form," South Atlantic Quarterly 96, no. 3 (1997): 499- 514, and Intensive Science and Virtual Philosophy (London: Continuum, 2002).

${ }^{44}$ For an extensive and detailed discussion of these issues, see Brett Buchanan, OntoEthologies: The Animal Environments of Uexküll, Heidegger, Merleau-Ponty, and Deleuze (Albany: State University of New York Press, 2008).
${ }^{45}$ Colin Ellard, Where Am I? Why We Can Find Our Way to the Moon but Get Lost in the Mall (Toronto: HarperCollins, 2009). 46 The account of Puluwatan navigation given below is derived from Edwin Hutchins, Cognition in the Wild (Cambridge, MA.: MIT Press, 1995), esp. 65-92, and Thomas Gladwin, East is a Big Bird: Navigation and Logic on Puluwat Atoll (Cambridge, MA.: Harvard University Press, 1970).

${ }^{47}$ Edmund Husserl, "Foundational Investigations of the Phenomenological Origin of the Spatiality of Nature: The Originary Ark, the Earth, Does Not Move”, in Husserl at the Limits of Phenomenology, ed. L. Lawlor and B. Bergo (Evanston, IL: Northwestern University Press, 2002), 117310. Thor Heyerdahl, Kon-Tiki: Across the Pacific by Raft (New York: Pocket Books. 1984).

${ }^{48}$ See note 7. 